\title{
DISCURSIVE PRACTICES OF MEDIA CULTURE: CULTURAL ASPECT
}

\section{Adriana Skoryk}

\section{INTRODUCTION}

In the broadest sense, the intrinsic function of culture is to preserve the different values and achievements of Humanity. Therefore primarily, by its ontological essence, culture is a medium for enunciation of a meaningful existence and it is a very essence of a meaningful existence. Therefore, a language must arise by means of which the sphere of values itself becomes recognizable and meaningful. The language of intrinsic ideas of a given culture, which organizes and directs its sense-making function, becomes such a language (and it is characteristic for every possible historical type of culture).

Namely in the aspect of "meaningful enunciation" in the culture of the new millennium an assumption was made that the discourses and discursive practices used in the field of contemporary humanitaristics, in particular in cultural sciences, create a homogeneous field and have a clear set of established characteristics which would be interesting to analyze.

First of all, we proceeded from the fact that a discourse means a verbally articulated form of objectification of the content of human consciousness in this particular era, governed by a type of thinking, dominant in a certain sociocultural tradition.

This concept gains a particular importance in the problematic field of cultural studies ${ }^{I}$. Just here discourse appears in the focus of attention, undergoing some kind of renaissance of meaningfulness: the discourse is considered to be a significant element of socio-cultural interaction. Thus, first of all, discourse is a language, immersed into a life and social context. But it is not an isolated textual or interlocutory structure. In the process of development of discursive analysis as a specific field of humanitarian researches it becomes clear that the meaning of discourse is not limited by written or oral language, but it also determines extralinguistic semiotic processes.

Thus, for adequate analysis of thinking activity, it is extremely important to fix the boundaries of the discursive sphere. The space of discursive

\footnotetext{
${ }^{1}$ Режим доступу: https://uk.wikipedia.org/wiki/Культур ологія
} 
practices $^{2}$ is associated with an ability to combine different-time, diverse, unpredictable, uncontrolled, spontaneous, etc. events in speech, reproducing the dynamics of the real.

Each type of discourse is based on a specific system of key aspects of cognition grounded in acquisition, use, storage and production of knowledge, each of them receives a specific semantic content in a particular discursive practice.

A cultural discourse ${ }^{3}$ is constituted as a discourse of awareness of culture in the aggregate of its comprehensive historical forms. It reconstructs the cultural universe (the "picture of the world"), which defines a holistic worldview of a person of a certain historical period. The article contains the analysis of interdependencies of the elements of discourse in the aspect of a unique phenomenon - a modern media space.

\section{Mass media: a system of related types of discourse in the problematics of contemporary cultural studies}

Beginning its history since Antiquity, the concept of "discourse" takes the position of one of the most important modern thinking concepts.

The first concept of discourse as a certain definition in the scientific debate was introduced by Roland Barthes: "We shall therefore take language, discourse, speech, etc., to mean any significant unit or synthesis, whether verbal or visual: a photograph will be a kind of speech for us in the same way as a newspaper article; even objects will become speech, if they mean something".

H. Marcuse introduced the "scientific fashion" of discourse, using this term in his work One-Dimensional Man. Quoting R. Barthes as an authority, G. Marcuse uses his conception and interpretation of discourse. After H. Marcuse's book gained a worldwide popularity, the discourse became the most widely accepted concept in the theories of society. In 1969, two French researchers continued to elaborate the theory of discourse. First of all, it is the doctrine of M. Pêcheux, who bases himself on the ideas of L. Althusser about ideological formations and M. Foucault theory of discursive formations. It should be noted that R. Barthes and $\mathrm{H}$. Marcuse concept of discourse gave rise and was completely assimilated by M. Foucault's concept of discourse. However, in his turn, M. Foucault also had a great influence on the ideas of R. Barthes.

The most appropriate for our study is M. Foucault ${ }^{4}$ theory. In order to understand the completeness and semantic diversity of the term "discourse", we'll cite a rather broad definition of the thinker: "The term discourse, which

\footnotetext{
${ }^{2}$ Режим доступу: https://uk.wikipedia.org/wiki/ Дискурс

${ }^{3}$ Режим доступу: http://oaji.net/articles/2017/294-1521575884.pdf

${ }^{4}$ Режим доступу: https://uk.wikipedia.org/wiki/Мiшель_Фуко
} 
I have used and abused in many different senses: in the most general, and vaguest way, it denoted a group of verbal performances; and by discourse, then, I meant that which was produced (perhaps all that was produced) by the groups of signs. But I also meant a group of acts of formulation, a series of sentences or propositions. Lastly - and it is this meaning that was finally used (together with the first, which served in a provisional capacity) - discourse is constituted by a group of sequences of signs, in so far as they are statements, that is, in so far as they can be assigned particular modalities of existence. And if I succeed in showing, as I shall try to do shortly, that the law of such a series is precisely what I have so far called a discursive formation, if I succeed in showing that this discursive formation really is the principle of dispersion and redistribution, not of formulations, not of sentences, not of propositions, but of statements (in the sense in which I have used this word), the term discourse can be defined as the group of statements that belong to a single system of formation; thus I shall be able to speak of clinical discourse, economic discourse, the discourse of natural history, psychiatric discourse".

And further: "The conditions determining the elements of such redistribution (objects, modality of statements, concepts and thematic choices) we call the rules of formation - rules of application (but also, of the existence, support, change and disappearance) in the discursive data redistribution". In other words, the discursive formation may be called a set of knowledge, verbalized in a regular way and necessary for formation of any particular science. Thus, the discourses are at once means and result of knowledge formation; they differ depending on certain knowledge specificity. Therefore M. Foucault distinguishes such discourses as economic, natural-historical, medical, philosophical, religious, and etc., but with an important reservation: the science (and knowledge itself) within margins of which the discourse is developing must be mature and such one that has happened.

Restricting the activity of people to their linguistic (that is, discursive) practices, the scientist comes to a conclusion that each scientific discipline has its own discourse represented by a "form of knowledge" specific for this science - a conceptual apparatus with thesaurus interrelations. This is what the work Archeology of Knowledge ("L'archéologie du savoir") says. Displaying the concept of discourse, M. Foucault treats discourses not only as a set of signs, but as certain practices (discursive, linguistic) that constantly form the objects they are talking about. According to M. Foucault, all the facts of culture fit into the context of "discursive" practices. "Discursive," according to Foucault, does not mean "rational," "logical," or "linguistic" in the direct sense of this word. Discourse is a midpoint between common rules and individual phenomena; it is a sphere of conditions of capability of language and cognition. And thus, discursive practices rather than exclude 
other types of social practices, on the contrary, admit them and require coupling between them. This creates the concept of "universality of discourse".

The discursive practice, according to M. Foucault: "Is a body of anonymous, historical rules, always determined in the time and space that have defined a given period, and for a given social, economic, geographical, or linguistic area, the conditions of operation of the enunciative function" ${ }^{5}$. Such practices are subject to the rules of formation, existence and coexistence, systems of functioning and etc. The main feature of such practices is pre-sign, pre-semiotic level of discursive, linguistic practices, which determine the conditions for the capability of signs, languages, logic and knowledge. On the surface of discourses, according to M. Foucault, the relationships that make them visible are determined. This principle of analysis the thinker calls the "Rule of The External".

M. Foucault ${ }^{6}$ tries to find such rational forms of analysis that would not appeal to the idea of the subject. He separates the central construction in the form of a "discourse on limit-experience" that helps the subject to transform himself and "a discourse on the transformation of himself through the formation of knowledge". Understanding the subject as a point of different historically formed discourses crossing, M. Foucault separates the language, text, and discourse as metaphorical designations of an all-pervading principle that helps him correlate and optimize these sociocultural phenomena. Thus, according to $\mathrm{M}$. Foucault, first the experience of borders crossing within the practices of language is analyzed, and then the work of thought over itself in a space of possible "limit-experience" is actualized. It refers to a certain transgression as an experience of crossing borders, as a "Gesture Facing The Border". To be more precise, crossing the border, beyond which the basic values and sense of the traditional cultural world loose their meaning.

This idea acquires a particular importance exactly nowadays, since the discourse of modern mass media has no boundaries in space at all, and hence a completely different meaning of the concept of "information space" arise, which will be discussed a bit later in our study. According to the opinion of French culturologist, modern culture may be expressed in a different language, not related to tradition at all. Such a transformation of language leads to change of style and profound shifts in the way of thinking, immersing the thinking experience into a language that "says what cannot be said."

\footnotetext{
${ }^{5}$ Режим доступу: https://alhassanainnetwork.wordpress.com/tag/the-enunciative-function/

${ }^{6}$ Режим доступу: https://uk.wikipedia.org/wiki/Мішель_Фуко
} 
In this way, Foucault connects the discourse with socio-cultural factors. He carries out this immerse into a specific conditions of place and time by means of "discursive practice" concept.

It should be noted that the famous German philosopher, sociologist, representative of a new generation of "Frankfurt School" J. Habermas repeatedly emphasized the fact of correlation or overlapping of philosophical concept of the phenomenon of "discourse" with its ethical and aesthetical load, and we shall add: a modern concept of the discourse acquires a transcultural nature and pervasiveness of this phenomenon in all spheres of being and existence. That is why, philosophers, sociologists, philologists, cultural scientists, art critics, and others work within the limits of contemporary research paradigm of mass media discourse. Thus, the importance of communicative, interdisciplinary, interpersonal and other relations in the contemporary information environment and artistic (on-screen) culture, etc. can be best demonstrated through the example of the analysis of the phenomenon of discourse.

The discourse, by J. Habermas, is constituted by communication. In this context, the social aspect of discourse is of the greatest interest. The thinker identifies five types of discourse that are realized in communication depending on the situation:

- a theoretical one, which is being organized on the basis of cognitive and instrumental mechanisms;

- a practical one, which is connected with moral and practical aspects and relies on the determination of correctness and norm of action;

- a discourse in the form of aesthetical criticism, which is evaluative by nature and is being constructed on the basis of correlation with value-based standards;

- a discourse in the form of therapeutic criticism, the main characteristic of which is expressiveness and the veracity of expressions;

- a discourse of self-expression and self-explanation, which is determined by the achievement of the intelligibility of what is being expressed and based on the correctness of symbolic structures formation.

In the book Knowledge \& Human Interests he proposes to divide three kinds of interests, transforming in a later period of creativity, into three worlds of a human. The first world is objective, the other one is social or intersubjective, and the third one is subjective or expressive. The cognitiveinstrumental discourse relates to the first world, the moral-practical discourse relates to the second world and ethical-aesthetical discourse relates to the third one.

Offering a social-communicative interpretation of discourse, J. Habermas relates the concept of discourse to the theory of social action - strategic, 
normative, dramatic, communicative, as well as the problem of social legitimacy. He especially distinguishes the so-called discursive communication, which is characterized by the thinker as free and consensual one. J. Habermas considers this type of communication to be an ideal communicative model, for what the opponents of this theory of communicative action have repeatedly reproached him. At the same time, he proceeds from the fact that the communicative actions studied by him are completely consistent with real features, various aspects of the actions and interactions of individuals in a true history.

Besides, the fact, that $J$. Habermas recognizes a discourse as a dialogue, in the course of which a reconciliation of conflicting claims for the significance of something in order to reach agreement takes place, is extremely important for our study: the discourse is involved into a dialogue between "one's own" and "another's", in a word, and into an analysis of an interpretation of the world and attitude to the world at the level of perception of a foreign language. Staying on the subtle border between inter-intentionality and reflexivity, the discursive practices (in the broadest sense) become assistants in the complex searches for the image structure of the works of culture and, in particular, of artistic and on-screen culture.

In opinion of J. Habermas, the basis of the discourse is a category of public sphere: just in it the discourse is exercised. The German thinker has two concepts of understanding the public sphere. For the first one the civil society ("Structural change of the public sphere") emerges as an intrinsic point of thoughts. Russian politologist A. Zinoviev, analyzing J. Habermas work, points out that a public sphere (Oeffentlichkeit) is such publicity (Oeffentlich), which existed in contrast with the privacy in Ancient Greece (public sphere and private sphere).

Determining the second concept of public sphere in The Theory of Communicative Action, the thinker writes about a break from the notion of civil society. Habermas notes that the public sphere is localized in the sphere of lifeworld (Lebenswelt). The later emerges as an addition to the communicative action as a sphere of understanding. The lifeworld is integrating socially via everyday communications and coordination of actions on the basis of understanding. It is divided into two spheres: at first communications aimed at private interests, and secondly - communications aimed at common interests, it means the public sphere. Thus, public sphere is considered to be a sphere of communicative action aimed at common interests. It is a set of ordinary non-private communications, opposing in modern life, for example, political and economic systems, which are integrated by means of power and money. Thus, this concept points to a certain danger for the public sphere in terms of commercialization of its structures. 
It should be noted that functioning of modern mass media (mass media) in the public sphere makes the situation even more complicated. The dominant totality of discursive formations has found an ideal mechanism for its existence in the media. More often a large proportion of the population is no longer able to form their own personal opinion, which means that they are overwhelmed by the consensus of those involved in discourses.

There is an uncertainty in interpretation of discourse in modern humanitaristics. M. Stubbs ${ }^{7}$ distinguishes three main features of discourse: 1) in the formal sense, it is a unit of language that exceeds a volume of a sentence; 2) in regard to the content, the discourse is connected with use of language in a social context; 3 ) the discourse is interactive by its organization, it means it is dialogical by nature. ("It refers to attempts to study the organization of language above the sentence or above the clause, and therefore to study larger linguistic units, such as conversational exchanges or written texts. It follows that discourse analysis is also concerned with language use in social contexts, and in particular with interaction or dialogue between speakers").

The next well-known researchers of the concept of discourse were L. Althusser, J. Derrida and J. Lacan. This French school characterizes philosophy and historicity of the discourse, its analytical aspect. Here, discourse is explored as a report, speech, words. A certain type of discourse includes its style, linguistic flow, certain sensual aspects represented by a particular kind of art.

Thus, the discourse category has many scientific interpretations; because it is a phenomenon of intermediate character between speech and communication, as well as linguistic behavior - on one hand, and on the other - it is fixed by the text. It should be noted that in the study of discourse at the end of the twentieth century a communicative approach is finally established, it is based not only on the creation of a new categorical apparatus, but also on the rethinking of existing terms: the speaker's native language flux is formed as a polycytate phenomenon, which includes many ready-made "communicative fragments", as well as the result of the linear construction of language system units.

We have already noted that the discourse admits a plurality of dimensions. The semiotic understanding of the term "discourse" provides other (it can be called structural) classification of types of discourse. In their Explanatory Dictionary Of The Theory Of Language Algirdas J. Greimas and J. Courtés interpret the discourse, from the one hand, as a "semiotic process", which, in turn, should be understood as "all the variety of ways of

\footnotetext{
${ }^{7}$ Режим доступу: http://eprints.zu.edu.ua/7168/1/12gnogpd.pdf
} 
discursive practice, including linguistic practice (types of verbal behavior) and the practice of the non-linguistic (meaningful behavior manifested in accessible for sensory perception forms - gestures, etc.)". However, taking into account "linguistic practice only", the scientists consider the discourse as an object of scientific discipline Linguistics of Discourse, or Discourse Linguistics (linguistique discursive), noting that in this sense discourse will be synonymous with the text: "In fact, in some European languages, which did not have a term equivalent to the Franco-English "discourse", they were forced to replace it by the term "text" and, accordingly, to speak about linguistics of text (linguistique textuelle). Besides, by means of extrapolation as a useful hypothesis, the terms "discourse" and "text" have also been used to refer to non-linguistic semiotic processes (ritual, motion picture, comic book are considered in this case as discourses or texts)". In the third sense, which is not contrary to the previous ones, the discourse is identified by the authors with the statement-result (énoncé). With respect to the latter, A. Greimas and J. Courtés introduce the concept of "discoursestatement": "The way in which the statement is understood more or less implicitly (as that which is spoken) defines two theoretical approaches and two different types of analysis".

The second perspective of the discourse typology is conditioned by narrativity (narration, descriptiveness) - a feature that characterizes a certain class of discourse, "on the basis of which the narrative types of discourse (narrative discourses) are distinguished from the types of non-narrative discourse". At this, a narrative discourse is embodied in the form of a story, and non-narrative discourse is realized in the form of a dialogue, but these two forms are almost never found in their pure form. It can be said that in any case a language always performs its main communicative function; it means that it primarily serves for information exchange between the people.

The mentioned contemporary culturologist and linguist V. Karasik ${ }^{8}$ offers to distinguish the approaches to discourse in a rather detailed way. We mean the following approaches:

- a pragmalinguistic one, which represents an interactive activity of communication participants, contact establishing and maintaining, emotions and information exchange, influentiality on each other, intertwining of instantaneous, variable communication strategies and their verbal and nonverbal embodiments in the practice of communication;

- a psycholinguistic measurement of discourse, as turning out of conversions from internal code to external verbalization in the processes of language generation and interpretation;

\footnotetext{
${ }^{8}$ Режим доступу: https://ru.wikipedia.org/wiki/Карасик, Владимир Моисеевич
} 
- a linguo-stylistic discourse, targeted at distinguishing the registers of communication, differentiation between oral and written language in their genre varieties;

- a structural-linguistic discourse, that provides its segmentations and is directed to elucidation of textual peculiarities of communication;

- a linguocultural discourse, meant to establish a specificity of communication within a certain ethnos, to determine formulaic models of etiquette and linguistic behavior, to define the cultural dominants;

- a cognitive-semantic phenomenon of discourse, which is studied in the form of frames, scenarios, mental diagrams, that means different models of communication representation in consciousness;

- a sociolinguistic approach to the discourse study, which involves the analysis of communication participants as representatives of a particular social group and the analysis of the circumstances of communication in a broad socio-cultural context. These approaches are not mutually exclusive.

In the context of our study, a particular interest is paid to an institutional discourse, which represents a communication within specified boundaries of status-role relations. The main participants in the institutional discourse are the representatives of the institution (the agents) and the people who appeal to them (the customers). There exists a principal degree of openness of the discourse between "the customers" and "the agents" in different institutional discourses. The author explained the term "institutional discourse" in such a way: "Institutional discourse is a specialized clichéd form of communication between people who may not know each other but who must communicate according to the norms of this society. Of course, any communication is of multidimensional, script-based nature, and its types distinguish with a certain degree of conventionality. A complete elimination of one's personality transforms the participants of institutional communication into dummies; at the same time, there is an intuitively sensible boundary for the participants of communication, the way beyond which undermines the foundations of the existence of a certain social institution".

The property of discourse to organize the means of the language system (language code) in communication under specific psychological and social circumstances in a most general way gives an opportunity to distinguish and characterize already known types of discourses. They are most completely classified by the scientist G. Pocheptsov. He distinguishes television and radio discourses, newspaper, theatrical, cinematic, literary one, a discourse in the field of public relations (PR), advertising discourse, political, religious (fideistic) discourses. Reviewing the discourse in modern culture, let us turn our attention on its literary and theatrical specimens as its verbal and spectacular-phenomenal visualization. 
A literary discourse is one of the oldest discourses. Rhythm and rhyme were its common characteristics. An artistic text becomes de-automated: the polysemy of the text for each one sounds similar to the concept of its own content in a particular work. The text gains a personal sense thanks to the reader; the "ciphers" of the text are deciphered every time by another reader or viewer.

The theatrical discourse can also be considered as belonging to a long life in society. Because, except the symbolic and character positions of theatrical discourse, such as scenery, clothing, lighting, it is based on a ritual that begins with the foyer and the wardrobe of the theater and ends with the last replica of the actor at the end of the performance.

The language and the theater arise as two parallel phenomena of sociocultural communication. The examples of their isolated and parallel existence are the examples of cooperation between individuals and groups that go back centuries. The origin of ancient philosophical thought clearly outlines the form of distinction and differentiation. Aristotle in his Metaphysics demonstrates to the reader the reproduction of terms with different meanings. In essence, this conceptual dictionary demonstrates that the Greeks developed the world's rhetoric. This means that we can talk about the beginnings of the intellect existence, about the shape-generating functions of the mind. At the same time, there is a rupture between mental and physical labor. This gave an incentive to the development of a new thinking and a new culture: WordSpeech-Rhetoric.

It is known that the first spectacles in the ancient world were theatrical performances in Ancient Egypt. There appeared the dialogues, monologues, songs and dances which were also the bearers of awareness of the population at that time.

Since such spectacles were the only cultured spectacular event in that time, it is difficult to overestimate their impact on the society of that time.

Greece is a country where participation in festivals and entertainment activities was encouraged at the state level. The rise of masses and the maximum of festive mood sound in the patriotic slogans of the polis. Doing so, the government fulfilled its duty and saved the demos. But let's not neglect the presence of heretics, different-minded, different-speaking at all times... Such an underground gave rise to its own aspects of discourse as a subject of linguistic exchange of thoughts, which sometimes avoided the acquisition of individual traits.

As a form of culture, the theater and everything associated with it had its logic of development, the core of which remains both language and communication. Its specificity depended on the genre of theatrical performance, and the specificity of communication of the auditorium - on 
those strata of society that filled it. But both the first and the second variants determined the advantages of the language environment in this context. First of all, the theater always relied on ancient mythology. That's what defines the control of the linguo-social environment, because mythsstories euphemistically made a secret out of the ancient times. A sign of an illusion or a truth, a reality or a deception - but, anyhow, it is embodied in the cultural message of theatrical gestures, facial expression and articulation. The correlation of something reproduced and heard provides the linguo-informational discourse, disguised as a theatrical action, with the tonalities of a struggle between good and evil, high and low, white and black. A performance, a play is a reality, language of the stage and the hall and of the backstage is, partially, an indeterminate outline, but it is an unconditionally recognized reality. The theatrical space was briskly filled with it.

Particularly an ancient dramatic art is a striking representative of the glorification of religion: the Greek theater was a temple, the altar of which was enveloped in grape clusters, and the performances became religious ceremonies that rather resembled Divine services.

The theatrical spectacle, its verbal content is a certain construction of the festival. It's a win-win schtick of the spectacular genre. And if communication is based on the constituent element of the theater-mystery as one of the initial phenomena of its existence, the focus of the dramaturges on the elements of textual poetics are the typical prerequisites for the origin of the concept of discourse, first of all, in the theatrical environment. The lack of mass media levers at that time (television, press, internet, etc.) only reinforced its role and importance in the society at that time. Sometimes these texts represented an abstract basis, mostly contained truth-loving characters. The people go to the theater not only for the sake of action, but also for the sake of the word. It seeks truth, affirms belief. The word becomes synonymous with art, the subject of a culture of existence and communication.

A linkage to a predominantly calendar show of mysteries has created another interesting detail - the gradual filling of dates (read "holy days") with its lexicon. The usability of Christmas performances is different in its lexicology from Easter ones; the tradition of ceremonial greetings and special verbal expressions migrates from the society to the stage texts. By means of discourse, the most successful ones become an integral attributes and their shining example. This is the boundary between the following types of theatrical performance: mystery, sacral and secular spectacle. The information carriers - texts, which occupy not the last place in the system of stage accomplishment of the performance, are controlled by the actor or creator. The illustrations, such as verbal "one-man show" are permissible. 
Here let's allow us to discuss the indisputability of interpretation, because just the literalism is perhaps the first impulse to bright reflectivity in acting profession as such, and to the internal emotional saturation of the actor's play. The cult of worship, veneration of the theater lies in the utmost respect to the Word. Being restricted by theatrical canons, it becomes decisive and completes the theatrical solution of the play, leaves the framework of the theater itself, disseminates the traditions of art. The Performer - Dialogue Communication model states that communication here uses language in the form of statements.

Identifying and analyzing the border zones in contemporary cultural studies discourse through the lens of reading, philosophy, linguistics, aesthetics, ethics, and other forms of knowledge, one more important point should be preserved. We mean mass media discourse as a socio-cultural phenomenon on the background of the dynamic changes of society, promoting the origin of more recent artistic and musical visions. To the point, the origin (occurrence) of mass communications predominantly firmly lies on the shoulders of the theater. Notwithstanding that our life is a continuous theater, let us start, citing M. Yevreinov, with the Greek definition of the "instrument" of contemplation - "theatron". As a rule, when we look we listen and talk. The journalistic context of the media space has always been in the genre of the theater. Its intelligent layer gave him "air." Notwithstanding that each era defined the attributes of the theater in its own way, life and years themselves defined the frameworks of its status. The genres of theatrical action provide the mass media discourse with a shape. The show, which is organized by the stage director and the actor, can be speechless or take the forms of radio perception by the audience.

Enlightenment is another function of mass media discourse: the desire to convey the information in a form that reflects the moral knowledge of the time. "The sixteenth century is an era of deep contradictions: Erasmus of Rotterdam and Montaigne belong to it, but also a Council of Trent implicates it too, a new astronomy coexists with the heyday of astrology, the renaissance of mathematics is accompanied by the popularity of magic and alchemy. The mentality of this century was as much based on the wisdom of the ancients as it was frivolous in the perception and selection of the wisdom of one's own time. Wild superstitions were neighbors with a refined and skeptical mind, an exceptional erudition - with the same astonishing gullibility and willingness to put fiction and the fruits of fantasy into the category of knowledge. Finally, despite the development of the book-printing, hearing still had an advantage over the eyes in the perception of information".

Ethical tonality of the epoch is an idea of nature serving to mankind, the triumph of good over evil actually made it possible to create the specifics of 
the linguistic space of that time and more clearly derive its model. Transformations and scientific masterpieces of discoveries in the fields of astronomy, medicine, botany and chemistry create the "vital force" and the perspective of the vital organism of the language.

\section{The forms of the discourse: activity and influentiality}

Thinkers of the XVIII-XIX centuries assert the priority of the spirit of a human being (a person). It is the fulcrum that will move the whole world. It should be noted that the great Ukrainians, such as G. Skovoroda ${ }^{9}$, N. Gogol ${ }^{10}$, P. Kulish and others reveal the spirit of the Human and his greatness through the lens of their vision of social problems solution by linguistic and information aspect. Notwithstanding that human activity is a threat to the planet, its continuous evolutionary progress sooner or later will transform it into spiritual values. The mysteries of human spirituality remain open. They are concentrated in the conditional expressions of humanity: sound, exclamation, statements, phraseologisms, philosophical thought. The unity of the determinant signs produces a great number of emotions, doubts, informativeness, creates music and painting. The synthesis of arts and verbal music creates a new vision on their essence and mission. The penetration of human language into the future may have an impact on the sequence of life events. In essence, the linguistic thinking forms our character. Having examined a long era of existence of Humanity, we can see the striking differences of each epoch, their phenomenon, the range of vital values, the demand for information stored in a single computer of Humanity - our heads. The internal and such invisible dialogue will surely produce a response. Any discourse in all its aspects (media, readers', theatrical, and etc.) includes both factual complexity and a high level of abstractions. Discourse is necessary to intertwine the motivations of many people in politics and business, to promote power structures, science, etc. Discourse is expected where you need to convince. The discourse statements for one purpose or another can transform public opinion, outline the things presented positively or negatively and sometimes even create the circumstances for further action of thought. A characteristic feature of the discourse is an attempt to be a bridge of understanding between discussion "camps" and the basis of certain decisions. A mediation of discourse through its persuasiveness and conquest retain it the right to ambiguity. Imagery is perceived by the subconscious. For example, an argumentation in a publicistic discourse is unfolded in a bright, expressive, multifaceted, sometimes unexpected language. It is fraught with intelligence

\footnotetext{
${ }^{9}$ Режим доступу https://en.wikipedia.org/wiki/Gregory_Skovoroda

${ }^{10}$ Режим доступу https://uk.wikipedia.org/wiki/Гоголь_Микола_Васильович
} 
and high ethicality. In literary discourse it is in a colorful, organic language, in music - it is filled with the expression of sounds, in theatrical one - almost in a theatrical effectiveness of a sustained play ... The phenomenon of a discourse language is a condition of its existence. Even the first ancient theaters, the ways of communication in them and psychological analysis of personality have built a peculiar model of the language pyramid of this epoch and this environment. The period easily defines the classification of characters, distinguishing the ancient model of temperaments. Clearly this type is manifested in communication - communication of stage speech, dialogues and monologues, theatrical acts and cues. An indicator of this type of communication is the sociological analysis of the linguistic personality. Representation of a person (personality) in a language can be offered through the lens of analysis of participation in a particular discourse. The pragmatism of such phenomena lies in highlighting of the clarity of the subject and the tonal communicativeness that characterizes the subject matter of a particular discourse. The discourse can be understood by the mediation of a text (a newspaper, a book), a conversation (TV interview, TV narration, radioprograms), vision (graphics, painting), aural worldview (music). Actually here we distinguish both the signs of the participants of the communication and the basis of the tonality of this communication. A pronounced analysis of a person from the standpoint of any discourse is a communicative tonality. And notwithstanding that in this case for such division we use the principle of content priority and concretization of the subject, the division of discourse by type of multifaceted conception of discourse, a certain type of reaction to it, the types of communication itself in discourse (for example, joke or grotesque, etc.) are of great importance here. The participants of an action can consume the subject in its direct meaning or identify it with something they are talking about. The changes of this "language" are possible with additional introduction of rhetoric, certain interpretations and ambiguous statements.

Sensitivity is an important feature of each type of discourse. The range of its amplitude fluctuates depending on the brightness of artistic embodiment: in music it depends on the essentials of feelings and world perception, as well as intellectuality of definition of ideas; in painting and graphics the tonality of coloristics and volumes are essential; in conversational discourse the motions of speech tones and placed touches of accents play an important role, etc. The discourse intonations are a residual effect of their existence.

It is clear that non-confrontational discourse is the most acceptable one. The discourse can also be considered as one of the forms of acceptance (perception) of everything that surrounds our society. In this case, its characteristic features will be the study of the subject (theme), the composition of the structure, integrity, comprehension, constancy. 
Objectivity (objectification) belongs to any subject; this feature is created and acquired by a human being himself. On the basis of joint activity of a number of analyses a holistic image arises: a system of knowledge about the properties of a particular discourse constitutes a basis for it. Reflection of the theme of its subject and the peculiarities of the subject itself are a source of the discourse integrity. Its peculiarity is a constancy of perception of the conditions of discourse, because mainly in the life the perception of objects constantly changes.

It is interesting to study the language of national music in the postmodern discourse. The concept of pluralism represents here a discussion about the destructive or creative value of the avant-garde related to the category of musical language. The "interpretive" nature of the Ukrainian neo-avant-garde manifests itself in the fact that its national rootedness is not discernible only at the level of mentality, worldview and aesthetic priorities. A one-dimensional, multidimensional presentation of ethno-specific material with an attempt to reproduce its authentic sound as accurately as possible (right up to use of folk instruments and folklore manner of singing) and to reconstruct the definitive structure of the folklore source sonor, that have almost never been "highlighted" in previous types of its processing, became their unifying invariant. This new, higher level of national identity comprehension did not consist in more or less successful subordination of ethno-specific material to the established rules of musical professionalism. The verbal artistic creation of an ancient art in our case can be considered as a prerequisite for the origin of mass media discourse in the modern sense. Humanity created it for itself and for its time. Discourse (read " artistic creation") helps to activate social processes.

In the basis of any discourse, especially the mass media one, we must first distinguish linguistic communication and the visual backdrop process of cognition. These two concepts, which are united by the definition of discourse and the movement of thinking from one to another, connect one opinion with another; make conclusions on connecting together already known signs. The question, with which namely of the traditional branches of culture and art the culture of linguistic communication should be identified, remains rhetorical. So, let's say, the oratorical art is the closest to politics and jurisprudence, the artistic word is the closest to art, organizational language functions are the closest to ethics. Elementally, language communication has a common methodological and technical organization.

What for are we talking and creating? Actually mass media become a communicative nucleus of conscious creation of modern culturology directions. Such a view makes it possible to observe the centuries-old accumulations of artistic heritage of Ukraine, to come to the analysis of their 
structure, to develop theoretical positions of scientific analysis, to make a model of perspective in accordance with professional and cultural tasks. Information communication evolves from the art of persuasion to the art of prudent and critical thinking, from philosophical meditation and polemic to technical propaganda and means of manipulation of public opinion. It has been found in various fields of practical use of oral speech by the society stage language, artistic reading, art of public speaking and others.

Mass-media language ${ }^{11}$, which was mostly based on the concepts of rhetoric, is regarded as universal means of human communication. As an incentive discourse it evolves from the art of persuasion to the art of reasoning, taking into account the circumstances of any person's life situations and actions.

Social system liberalization is accompanied by increased attention to the aspirations and desires of the individual. Freedom of speech and awareness provide the ability to exercise that right. Lack of democratic freedoms is tantamount to lack of mass media awareness. The language, which is its only key unit, acquires dominant features here.

F. Nietzsche expressed an idea, according to which two opposite principles - Apollonian (creative) and Dionysian (destructive) are present in the life. Creative and destructive are under the influence of the power of human word. Beneficial and pacifying influence transforms the word into a cultural phenomenon. Influentiality is to earn confidence and a great reputation for the future. A striking TV performance or an article in the newspaper creates the speaker's influentiality, because he persuades the audience in favor of his speech. The emotionality of one speech evokes strong emotion of the other party. Speech (or press publication) itself should have unique value; it should form an intention to do something and change the mood and thoughts of the audience. The subject of mass media discourse in culturology emphasizes one more its aspect - the problem of motivation of performances. It is extremely important for characterization not only the speaker but also the listeners. Giving a lecture, the speaker can be guided by the desire to impress, and listeners may feel curiosity, fear and compassion.

The primary comments here are on the subject matter of the speech, analysis of the audience and situation of speechification. From a scientific point of view, preparation for such a speech is interpreted as a solution of a communicative task, which is to find the linguistic means of reaching the necessary for the speaker response of the audience. The following operations include the preparation of an outline plan, which should consist of separate sentences of the subject-predicate structure. Alphanumeric characters and

\footnotetext{
${ }^{11}$ Режим доступу: https://uk.wikipedia.org/wiki/Засоби_масової_інформації
} 
indentation systems make semantic connections between the sentences. The following is the composition of the speech (introduction, main part and conclusion). The subsequent development of the content of the speech goes through the stages of attention arresting, satisfaction of need, call to action or approval. The "visualization" of the proposed solution is especially effective for TV-mass media: the video screening here is the result of the proposal. And the final stage is displaying by the audience its particular acts - the emotions and beliefs that have arisen in the result of conversation.

\section{CONCLUSIONS}

The realization of the purpose and objectives of art permits a resort to media discourse in the extended sense. For language communication, the rhetoric acts as a theoretical basis that distinguishes the contexts of language arts implementation. Mass media get an opportunity to capture a large part of mass audience; they become liberal in the sense of mass accessibility. The methods of mass media implementation become rational. The existence of a computer accustoms to rational organization of communication and highly reasoned considerations. Feelings go away but the evidence is eternal. The demonstrative feature of a visual backdrop brought the methods of persuasion and building trust. Considering the public language communications that make the basis for the mere existence of the concept of media discourse, we face the problem of the conformity or nonconformity of creative individuals (editor, journalist, cameraman, director). These contradictions lead to a comprehension of tendencies, essence and specificity of contemporary journalism - newspaper or electronic, its tasks and functions in the field of human modeling in the world of media and critical art history work. The mass media discourse (rhetoric and the art of language that became its founders) interchanges in its aesthetic and pragmatic functions, because a modern scientific and technological progress raises new issues related to creation of artificial intelligence and control of human consciousness, which receives and stores the information in the process of communication, and general tendency to social life liberalization. This will undoubtedly lead to a new function of mass media in the context of "cultural conversation".

In the modern globalized world marked by the significant interplay of different information layers - not only vertically (of different historical periods) or horizontally (of different national cultures and traditions), but also diagonally (of different ontological and cognitive levels, for example artistic, political, economic, religious spheres) - any differentiation of texts will always be in a certain sense relative and conditional. Artistic communication borrows the instrumentarium of documentary modus. Everything surrenders to influence efficiency increase. Due to this, the rules of the communicative space can be framed as certain rules of attraction and repulsion. 


\section{SUMMARY}

1) The mass media discourse is always emotionally colored, since its main purpose is to influence consumers effectively.

2) The mass media at all times were aimed at manipulating the consciousness of the recipients, both in an open and a hidden form.

3) The hallmark of mass media discourse in contemporary culturology is the possibility of a new integrative knowledge, as traits of postmodernism epoch.

4) The integrativeness is an important feature of mass media discourse in contemporary culturology.

5) As all cultural facts fit into the context of certain discursive practices, communicativeness is one of the dominant features of a new integrative knowledge.

6) It is important that dialogueness requires interconnectedness of discursive practices, interconnection between them or exclusion of such practices. The cultural discourse of mass media is involved in a dialogue between "one's own" and "another's", the analysis of worldview and world reception at the level of grasping a foreign language (in the broad sense of its understanding). For this reason, mass media discourse is a "language in a language" that is not possible outside of communicative acts (between subject and object, languages, texts).

7) The communicativeness of modern mass media discourse always exists alongside "live" dialogue. Besides, crossing the boundaries between "one's own" and "another's", the experience of crossing the "experiencesboundaries" (according to M. Foucault), borders in the context of mass media discourse is an act of transgression, going beyond the boundaries of understanding the basic value-based orientations and senses of the traditional cultural life.

8) A modern mass media discourse is increasingly acquiring transcultural features, aiming at the pervasiveness of this phenomenon in all spheres of being and existence. The transcultural tendencies towards discursiveness in mass media knowledge clearly speak about globalization processes taking place in the contemporary cultural space.

\section{REFERENCES}

1. Habermas J (1990). Strukturwandel der Öffentlichkeit : Untersuchungen zu einer Kategorie der bürgerlichen Gesellschaft. Frankfurt am Main : Suhrkamp, $391 \mathrm{~S}$.

2. Habermas J. (1990). Strukturwandel der Öffentlichkeit : Untersuchungen zu einer Kategorie der bürgerlichen Gesellschaft. Frankfurt am Main : Suhrkamp, $391 \mathrm{~S}$. 
3. Stubbs M. (1983). Discourse Analysis : The Sociolinguistic Analysis of Natural Language. Oxford \& Chicago : University of Chicago Press, 1983. 279 p. (Series : Language in Society. Book 4). S. 1.

4. Apel K.-O (2009). Diskurs und Verantwortung: the problem of the transition to post-conventional morality / [translated by V. Kuplina]. K. : Dukh I Litera, 430 P. (Modern Library of Humanities).

5. Barg M. A. (1987). "Philosophical story" Enlightenments. Eras and ideas: the formation of historicism. M. : Mysl, P. 291-341. P. 74.

6. R. Barthes Mythologies (1989). / Roland Barthes; [compilation, general editing and introductory article G. K. Kosikova]. Selected works: Semiotics. Poetics. M. : Progress. P. 210.

7. R. Barthes (1975). The Elements of Semiology Structuralism: Pros and Cons: digest of articles. M. : Progress. P. 292.

8. Algirdas J (1983). Greimas Semiotics : Explanatory Dictionary Of The Theory Of Language / A. J. Greimas and J. Courtés; [translated by V. P. Murat]. Semiotics [compilation, general editing and introductory article Yu. S. Stepanova]. M. : Raduga, 638 p. P. 488.

9. Algirdas J (1983). Greimas Semiotics : Explanatory Dictionary Of The Theory Of Language / A. J. Greimas and J. Courtés; [translated by V. P. Murat]. Semiotics [compilation, general editing and introductory article Yu. S. Stepanova]. M. : Raduga, 1983. 638 p. P. 488-489.

10. Algirdas J (1983). Greimas Semiotics : Explanatory Dictionary Of The Theory Of Language / A. J. Greimas and J. Courtés; [translated by V.P. Murat]. Semiotics [compilation, general editing and introductory article Yu.S. Stepanova]. M. : Raduga, 1983. 638 p. P. 502.

11. Karasik V. I (2000). On Types of Discourses. Language Personality: Institutional and Personal Discourse: Scientific Works Collected. Volgograd: Peremena, S. 5-7.

12. Karasik V. I (2000). On Types of Discourses. Language Personality: Institutional and Personal Discourse: Scientific Works Collected. Volgograd: Peremena, 2000. S. 45-46.

13. Foucault M (2004). Archeology of knowledge / Michel Foucault,; [translated by M. B. Rakova, A. Yu. Serebryannikova ; introductory article. A. S. Kolesnikov]. SPb. : Academy of Humanities, Universitetskaya Kniga, 2004. 416 p. (Series : Ars Riga. French Collection).

14. Foucault M (2004). Archeology of knowledge./ [translated by M. B. Rakova, A. Yu. Serebryannikova ; introductory article. A. S. Kolesnikov]. SPb. : Academy of Humanities, Universitetskaya Kniga, 416 p. (Series : Ars Riga. French Collection).

15. Foucault M (2004). Archeology of knowledge. / [translated by M. B. Rakova, A. Yu. Serebryannikova ; introductory article. A. S. Koles- 
nikov]. SPb. : Academy of Humanities, Universitetskaya Kniga. 416 p. (Series : Ars Riga. French Collection).

16. Foucault M (2004). Archeology of knowledge / [translated by M. B. Rakova, A. Yu. Serebryannikova ; introductory article. A. S. Kolesnikov]. SPb. : Academy of Humanities, Universitetskaya Kniga. 416 p. (Series : Ars Riga. French Collection).

\section{Information about the author:}

Skoryk Adriana,

Prof.,dr.Hab.,vice-presidente for Reseach

Petro Tchaikovsky National Music Academy of Ukraine,

1-3/11, Architect Gorodetsky str., Kyiv, Ukraine

ORCID ID: https://0000-0002-4158-8352 